\title{
Experimental Study on the Combustion Performance of A New Biodiesel named Curcas Oil Diethylene Glycol Ether Ester
}

\author{
Yun BAI* \\ Miliary Basic Education College, Engineering University of CAPF, \\ Xi'an, ShaanXi province, China \\ e-mail:wanghe717@163.com
}

\begin{abstract}
In this paper, a novel biodiesel named curcas oil diethylene glycol ether esters was experimental studied on engine combustion characteristics, this biodisel and its mixed fuel were respectively tested through engine test and physicochemical properties bench. The results showed that curcas oil diethylene glycol ether esters had good physical and chemical properties; compared with diesel, the overall trend of the engine pressure dynamometer did not change significantly at the conditions of the same speed and loads, and its pressure rise rate and heat release rate both had a distinctive features of curved forward and peak reduction. Effective thermal efficiency increased with the content of biodiesel in blended fuel. This indicates that the novel biodiesel had a higher oxygen content and cetane number, therefore it owned excellent ignition performance, and can replace diesel as alone fuel.
\end{abstract}

Keywords- Biodiesel; Curcas oil diethylene glycol ether esters; Combustion characteristics; Physical and chemical properties

\section{INTRODUCTION}

Since some arable virtue of wide area adaptation, low cost, high production and no account of farmland, curcas oil had been more and more popular in recent years as the main raw material of biodiesel production [1-3]. Through the traditional ester exchange method, the curcas oil biodiesel had only one ester group, namely two oxygen atoms, so the oxygen was not too high to improve the combustion performance in the diesel engine. The ether group can improve both the ignition performance and the overall cetane number because of its excellent fire performance. With the increase of cetane number, carbon emissions will be further reduced. So it was very important to develop a novel biodiesel with high oxygen content by the introduction of ether groups to increase the oxygen content of molecules. In this paper, the physicochemical properties analysis and engine bench test of the novel biodiesel were carried out to verify if it can high improve the combustion performance.

\section{TEST SECTION}

\section{A. Physical and Chemical Properties Test}

Three kinds of fuel including 0\# diesel (B0), the mixed fuel with the volume content of $25 \%$ biodiesel (B25) and pure biodiesel (B100) were prepared to analysis of the physicochemical properties. The specific test methods were used as followed [4-6]: (1) oil solubility test; (2) copper corrosion test, using GB/T378-64 method; (3) density test, using GB/T1884-2100 method; (4) smoke test, using GB/T382-83 method; (5) kinematic viscosity test, using GB/T265-88 method; (6) flash point test, using GB/T261-83 method; (7) solid point test, using GB/T51083 method; (8) calorific value test, using GJB770A-97 (constant temperature method)

\section{B. Engine Combustion Characteristics Test}

A YTR2105 type diesel engine with four-stroke, forced water-cooled, direct-injection and twin-cylinder was used to research on the experimental combustion performance of curcas oil diethylene glycol ether ester, and its structure parameters was as shown in Table 1. The combustion characteristics of three fuels at 1500rpm and 2100rpm were analyzed at the different test loads with $20 \mathrm{~N} \cdot \mathrm{m}$, $40 \mathrm{~N} \cdot \mathrm{m}, 60 \mathrm{~N} \cdot \mathrm{m}, 80 \mathrm{~N} \cdot \mathrm{m}$ and $100 \mathrm{~N} \cdot \mathrm{m}$ respectively. A comparative analysis was made on the pressure of cylinder, pressure rise rate, heat release rate and effective thermal efficiency under various loads. As the curve of pressure rise rate and heat release rate were very similar for each other under different loads at the same speed, the results of tests on $10 \mathrm{~N} \cdot \mathrm{m}$ and $70 \mathrm{~N} \cdot \mathrm{m}$ loads were selection for typical analysis.

TABLE I. PARAMETERS OF YTR2105 TYPE DIESEL ENGINE

\begin{tabular}{ll}
\hline factor pattern & parameter \\
\hline combustion chamber form & $\omega$ direct injection type \\
cylinder bore*cycle & $105 \mathrm{~mm}^{*} 121 \mathrm{~mm}$ \\
output volume & $2178 \mathrm{~cm}^{3}$ \\
compression ratio & $17: 1$ \\
nominal output / rotating speed & $25.9 \mathrm{kw} / 2300 \mathrm{rpm}$ \\
maximum torque / rotating speed & $123.7 \mathrm{~N} \cdot \mathrm{m} / 1725 \mathrm{rpm}$ \\
fuel supply advance angle & $25^{\circ} \mathrm{CA} \mathrm{BTDC}$ \\
\hline
\end{tabular}

\section{RESULTS AND ANALYSIS}

\section{A. Physicochemical Properties}

Physicochemical properties of biodiesel named curcas oil diethylene glycol ether ester were shown in Table 2. The results were all in line with the EU biodiesel technology standard [7,8], which mean that the biodiesel can be used in any conventional diesel engine. 
TABLE II. PHYSICOCHEMICAL PROPERTIES OF CURCAS OIL DIETHYLENE GLYCOL ETHER ESTERS

\begin{tabular}{|c|c|c|c|c|}
\hline \multicolumn{2}{|c|}{ volume content of biodiesel/ $\%$} & 0 & 25 & 100 \\
\hline \multirow{2}{*}{ dissolubility } & $20^{\circ} \mathrm{C}$ & - & resolution & - \\
\hline & $40^{\circ} \mathrm{C}$ & - & resolution & - \\
\hline copper corrosion & & \multicolumn{3}{|c|}{ none phenomenon } \\
\hline \multicolumn{2}{|l|}{ density /g. $\mathrm{cm}^{-3}$} & 0.9081 & 0.9033 & 0.8883 \\
\hline \multicolumn{2}{|l|}{ smoke point $/ \mathrm{mm}$} & 24.5 & 17.8 & $>50$ \\
\hline \multicolumn{2}{|l|}{ flash point $/{ }^{\circ} \mathrm{C}$} & 57.0 & 190.3 & $>290$ \\
\hline \multicolumn{2}{|l|}{ solid point $/{ }^{\circ} \mathrm{C}$} & -11 & -8 & -4 \\
\hline \multirow{2}{*}{$\begin{array}{l}\text { kinematic viscosity } \\
/ \mathrm{mm}^{2} \cdot \mathrm{s}^{-1}\end{array}$} & $20^{\circ} \mathrm{C}$ & 4.5021 & 5.6425 & 11.164 \\
\hline & $40^{\circ} \mathrm{C}$ & 2.8400 & 3.4620 & 6.538 \\
\hline \multicolumn{2}{|c|}{ calorific value $/ \mathrm{kJ} \cdot \mathrm{kg}^{-1}$} & 43.500 & 42.036 & 37.642 \\
\hline
\end{tabular}

\section{B. Engine Pressure Dynamometer}

Engine pressure dynamometer of three different fuels including B0, B25 and B100 at two engine speed of 1500rpm and 2100rpm were shown in Fig.1 and Fig.2 respectively.

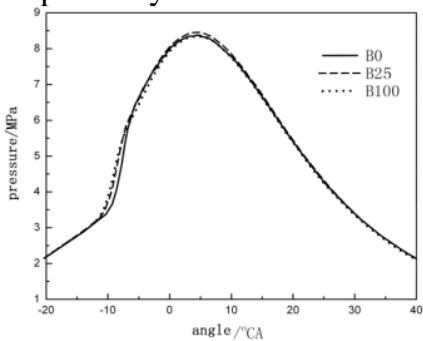

(a) $\mathrm{T}=10 \mathrm{~N} \cdot \mathrm{m}$

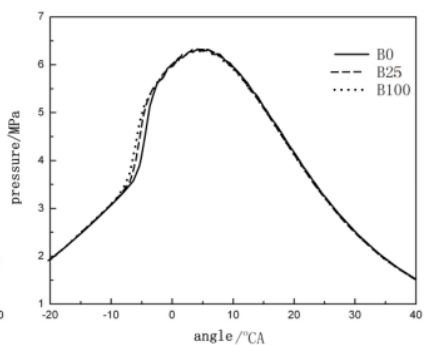

(b) $\mathrm{T}=70 \mathrm{~N} \cdot \mathrm{m}$
Figure 1. Engine pressure dynamometer at $1500 \mathrm{rpm}$

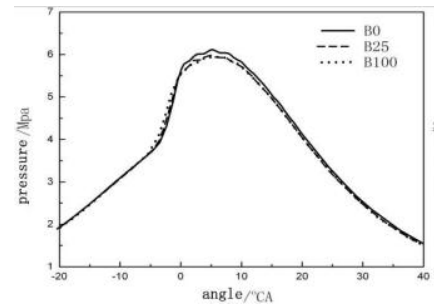

(a) $\mathrm{T}=10 \mathrm{~N} \cdot \mathrm{m}$

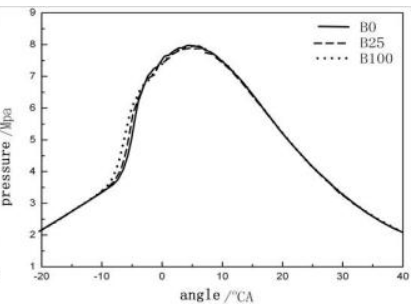

(b) $\mathrm{T}=70 \mathrm{~N} \cdot \mathrm{m}$
Figure 2. Engine pressure dynamometer at $2100 \mathrm{rpm}$

It can be seen from Fig.1 and Fig.2 that when fueling with curcas oil diethylene glycol ether ester, the overall trend of engine pressure dynamometer did not change much compared with diesel. These mean that the combustion of biodiesel almost no impact to the engine operating conditions. Under the same engine speed and loads, the curve of engine pressure dynamometer was moved forward when engine fueled with curcas oil diethylene glycol ether ester and its mixed fuel. That was to say the fuel ignition point had been advanced. For example, as burning B100, the curve of engine pressure dynamometer was moved forward by about $1.5-5.0^{\circ} \mathrm{CA}$, and the cylinder peak pressure was also decreased by about $6.2 \%-8.2 \%$ at the same time.

\section{Pressure Rise Rate}

Engine pressure rise rate of three different fuels including B0, B25 and B100 at two engine speed of 1500rpm and 2100rpm were shown in Fig.3 and Fig.4 respectively.

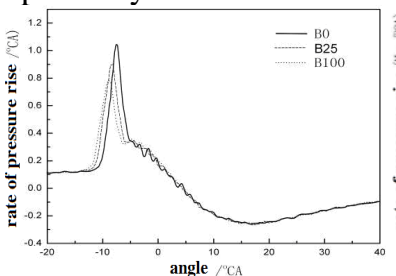

(a) $\mathrm{T}=10 \mathrm{~N} \cdot \mathrm{m}$

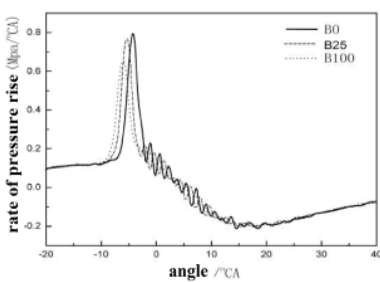

(b) $\mathrm{T}=70 \mathrm{~N} \cdot \mathrm{m}$
Figure 3. Engine pressure rise rate at $1500 \mathrm{rpm}$

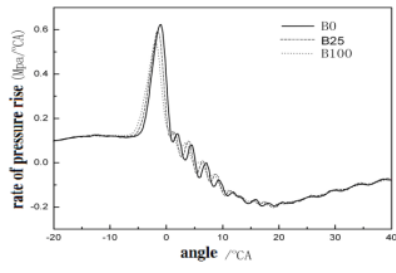

(a) $\mathrm{T}=10 \mathrm{~N} \cdot \mathrm{m}$

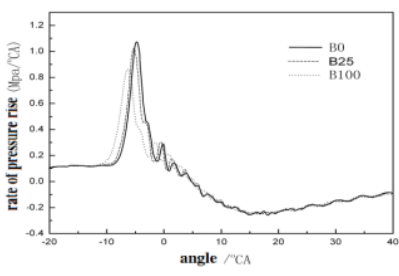

(b) $\mathrm{T}=70 \mathrm{~N} \cdot \mathrm{m}$
Figure 4. Engine pressure rise rate $2100 \mathrm{rpm}$

It can be seen from Fig.3 and Fig.4 that when burning $\mathrm{B} 100$ and $\mathrm{B} 25$, the curve of pressure rise rate had obvious advancement compared with $\mathrm{B} 0$, and increased forward about $2.5-6.0^{\circ} \mathrm{CA}$ for $\mathrm{B} 100$. In addition, the peaks of pressure rise rate for the two fuels were significantly decreased by $5.8 \%-24 \%$ and $15.3 \%-32.2 \%$ for B100 and B25 respectively under the same conditions. This was the further evidence that ignition point of curcas oil diethylene glycol ether ester and its mixed fuel were both early to diesel, which agreed with the changes of engine pressure dynamometer shown. Due to cetane number determining the ignition point of fuel, it was suggested that cetane number of biodiesel was higher than that of diesel, so that it can own the excellent fire performance.

\section{Rate of Heat Release}

Engine heat release rate of three different fuels including B0, B25 and B100 at two engine speed of 1500rpm and 2100rpm were shown in Fig.5 and Fig.6 respectively.

It can be seen from Fig.5 and Fig.6 that heat release rate of B100 was ahead of B0 significantly, the peak of curve was also significantly reduced, and the ignition delay period was shortened, which agreed with curves of pressure rise rate. Heat release rate of B25 was ahead of $\mathrm{B} 0$ about $2.5-3.0^{\circ} \mathrm{CA}$, and the peak was reduced by about 5.6\%-25.0\%; Heat release rate of B100 was similar to B25, which was ahead of than $\mathrm{B} 0$ about $0.3-6.0^{\circ} \mathrm{CA}$, and the peak was reduced about $17.8 \%-35.7 \%$. It was analyzed shows that no matter in which kind of speed condition, the curve of heat release rate of curcas oil diethylene glycol ether ester had obvious forward to diesel, and the peak also had corresponding decreased significantly; However, the higher the blending content of biodiesel, the greater the amplitude of decrease of the heat release rate. This was 
because the cetane number of biodiesel was much higher than diesel, leading to the ignition point of the mixed fuel ahead of time, shortening the ignition delay. However, biodiesel had a lower calorific value, lower combustion temperature, lower combustion temperature and lower volatility than that of diesel oil. Therefore, the curves peak of curcas oil diethylene glycol ether ester was lower than that of diesel.

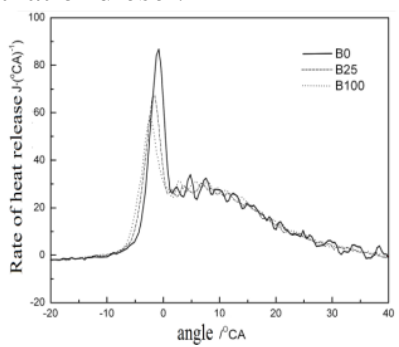

(a) $\mathrm{T}=10 \mathrm{~N} \cdot \mathrm{m}$

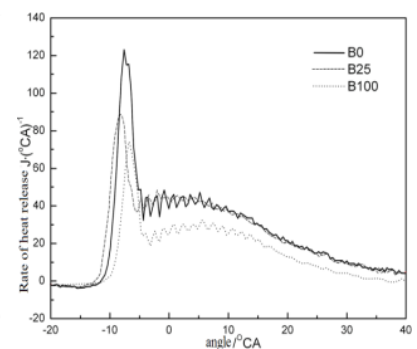

(b) $\mathrm{T}=70 \mathrm{~N} \cdot \mathrm{m}$
Figure 5. Engine heat release rate at $1500 \mathrm{rpm}$

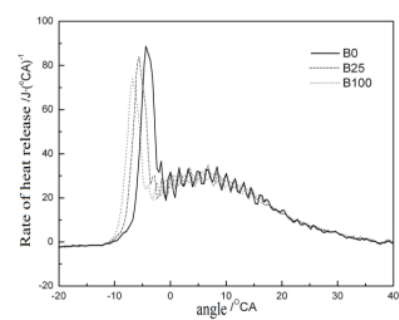

(a) $\mathrm{T}=10 \mathrm{~N} \cdot \mathrm{m}$

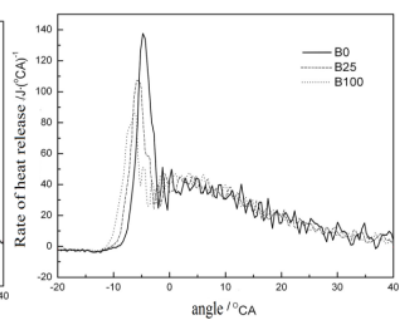

(b) $\mathrm{T}=70 \mathrm{~N} \cdot \mathrm{m}$
Figure 6. Engine heat release rate at $2100 \mathrm{rpm}$

\section{E. Engine Effective Thermal Efficiency}

The data and corresponding curve of engine thermal efficiency for three different fuels including B0, B25 and $\mathrm{B} 100$ at 10 kinds of different conditions were shown in Fig.7.

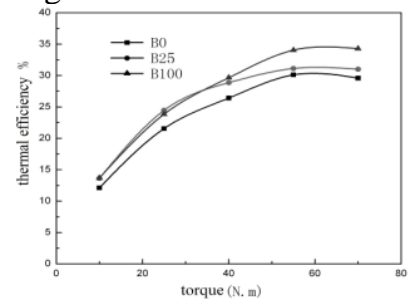

(a) $\mathrm{n}=1500 \mathrm{rpm}$

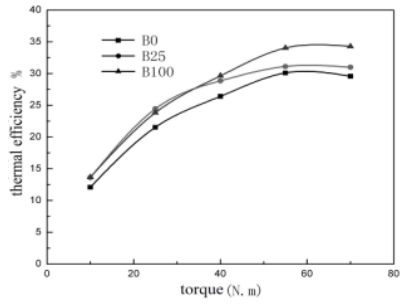

(b) $\mathrm{n}=2100 \mathrm{rpm}$
Figure 7. Engine effective thermal efficiency at 1500rpm and 2100rpm

Under the speed of 1500rpm, effective thermal efficiency of B25 was increased by $3.4 \%$ to $13.5 \%$, and that of B100 was also increased by $15.9 \%$ to $10.8 \%$. Under the speed of $2100 \mathrm{rpm}$, the effective thermal efficiency of B25 was increased by $13.6 \%$ to $3.4 \%$, and that of B100 was increased by $15.9 \%$ to $10.7 \%$. The analysis of the experimental data showed that the higher the content of the biodiesel in the mixed fuel under the same rotational speed and load condition, the more obvious the improvement of effective thermal efficiency. This was because the combustion process was improved, so the self-supplied oxygen capacity of biodiesel can improve the situation of local anoxia and the amount of premixed combustion, thus both combustion isovolumic and effective thermal efficiency were improved.

\section{CONCLUSIONS}

(1) Because curcas oil diethylene glycol ether ester had good physicochemical properties and combustion performance, it can be used as diesel fuel additive or can also replace diesel be used singly, and had certain value of popularization and application in the future.

(2) When fueled with curcas oil diethylene glycol ether without any adjustment for the engine parameters, engine operating conditions were followed that the engine ignition point was ahead of time; the ignition delay period was shortened; the peak of combustion pressure was decreased; curve of pressure rise rate was moved forward, and its peak reduced; curve of heat release rate was moved forward, and its peak was decreased; The higher the content in the mixed fuel, the higher the corresponding change

\section{ACKNOWLEDGMENT}

This work was supported by Grant (No. 2014JM7284) of the Natural Science Foundation of ShaanXi Province

\section{REFERENCES}

[1] D. L.Klass, Biomass for Renewable Energy, Fuels and Chemicals (Academic Press, New York, 2008).

[2] CBIW. 2010-2012 Report on research and investment analysis of China biodiesel market. (GC 2010720161448118, 2010).

[3] X. Zhang, H.Z. Li, X.S. Yan, Prospect of the biodiesel application. Public Utilities, 14(3): 7-9 (2010).

[4] W.F. Watts, M. Spears, J. Johnson, Evaluation of biodiesel fuel and oxidation catalyst in an underground metals mine. University of Minnesota journals, Vol.33(5), pp.66-70 (2008).

[5] Q.D. Huang, F.D. Huang, X.M. Guo, Production technology and development significance for Biodiesel. Journal of Cereals \& Oils, Vol.15(7), pp.17-21 (2002)

[6] K.D. Yong, K. G, Experimental study on preparation of biodiesel and exchange pretreatment of Jatropha oil ester. Renewable Energy Resources, Vol.27(2), pp.28-32 (2009).

[7] D.Y. Jiang, Preparation and characterization of a novel biodiesel with ether. Renewable Energy Resources, Vol.30(7), pp.74-78 (2011).

[8] D.Y. Jiang, Y. Bai, Performances on engine-out emissions and combustion of ethylene glycol monobutyl ether palm oil monoester as a new type biodiesel. Journal of Renewable and Sustainable Energy, Vol.4(5) ), pp.358-371 (2012).

[9] D.Y. Jiang, X.J. Wang, Y. Bai. Rapeseed Oil Monoester of Ethylene Glycol Monomethyl Ether as a New Biodiese. Journal of Biomedicine and Biotechnology, Vol. 2011, Article ID 293161.

[10] D.Y. Jiang, Wang Xenguo, Y. Bai. Exhaust emissions and combustion performances of ethylene glycol monomethyl ether palm oil monoester as a novel biodiesel. African Journal of Biotechnology, Vol.10(72), pp. 16300-16313 (2011). 